\title{
Alfabetización y lectura en Asturias durante la Edad Moderna
}

\author{
Baudilio Barreiro Mallón
}

\section{LA ENSEÑANZA PRIMARIA: DOTACIONES Y FINANCIACIÓN}

El acceso a la lectura y escritura durante el Antiguo Régimen era un problema no sólo de posibilidades sino también de opciones socio-económicas. En un mundo de carencias fundamentales no era suficiente tener la posibilidad de aprender, sino que era necesario advertir que estos conocimientos podian reportar ventajas significativas, circunstancia que tan sólo se daba en aquellos sectores que pretendían dedicarse a la Iglesia, a la Administración del Estado o al comercio.

Resulta sumamente significativa la lectura de los acuerdos municipales, pues pasan años y más años sin encontrar ninguna alusión a las cuestiones de enseñanza y, en cualquier caso, el nivel de interés del Regimiento siempre es inferior al mostrado ante los aspectos de costumbres, religiosos y hacendisticos.

Las Ordenanzas de Avilés de 1779 no hacen la más mínima alusión a maestros, preceptores, etc. El único párrafo que se aproxima algo dice asi: "todo padre de familia que incurriese en la omisión de dar destino a sus hijos llegando a la edad de diez y seis años, dedicándolos a alguna carrera onrosa u ocupándolo en algún exercicio provechoso (...) deberá el Ayuntamiento tomar providencia poniendo todos los medios necesarios". Pero con esto se evidencia que lo único que les preocupaba era el problema de la ociosidad con los peligros que ésta implicaba para la sociedad, como ellos mismos reconocían al justificar tales medidas para evitar aquellos hipotéticos peligros '.

\footnotetext{
1 A. M. Avilés, Ordenanzas de 1779, C. 95.
} 
La misma despreocupación se desprende de la lectura de las Actas de la Junta G. del Principado, pues desde 1606 hasta 1672 únicamente aparece una mención de la enseñanza secundaria (no de primeras letras), al interesar de la Compañia de Jesús que decida abrir escuela de gramática en Oviedo ${ }^{2}$.

Este desinterés oficial no parece que se modifique sinceramente con los ilustrados del siglo XVIII pues esbozan una política cultural apoyada en los siguientes principios: primero, mantenimiento de las desigualdades sociales (en clara contradicción con la afirmada igualdad natural); segundo, cultura utilitaria y dirigida (en aparente contradicción con el principio de bondad natural, según el cual el poder deberá limitarse a elimininar los estorbos que dificulten el avance hacia el progreso).

Como consecuencia lógica, la cultura escrita queda limitada a los grupos digentes y vedada a las masas populares, lo que quiere decir que se olvida la enseñanza primaria y se controla o persigue a las preceptorías de gramática para evitar la «huida del agro».

Que no tenía interés la enseñanza primaria lo evidencia el hecho de que durante el gobierno de Fernando VI únicamente se dictó una R.C. sobre la misma, sin interés especial. Los equipos de Carlos III ofrecieron buenas palabras - no sé si buenas intenciones- en favor del prestigio y reconocimiento social del maestro, pero sin traducción en medidas reales.

Sobre la realidad de los estudios primarios y la implicación o no de los regimientos concejiles en los mismos vamos a tratar a continuación.

Podemos reducir a cuatro los sistemas de dotación y financiación de los maestros de primeras letras de acuerdo con los datos documentales. Uno, el que abordan, parcialmente, algunos regimientos concejiles al financiar una parte del salario del maestro con los bienes de propios. Este es el caso, por ejemplo, del Concejo de Somiedo que lo hace gracias a los importantes ingresos que obtiene del arriendo de sus pastos a los ganaderos trashumantes. Entran igualmente en este grupo Gijón, Avilés y Oviedo, municipios que carecen de propios significativos, pero que se «apropiaron» de la administración de las rentas provinciales y con el

\footnotetext{
2 Actas Junta G. Princ., T. VII, p. 182. Ed. Oviedo, 1964.
} 
beneficio de esta administración consiguen financiar gran parte de sus gastos municipales ${ }^{3}$.

Un segundo grupo lo forman algunos pueblos cuyas Fábricas Parroquiales cobran derechos decimales que les capacitan para afrontar no sólo sus gastos específicos, sino otros como es la contratación de un maestro-sacristán. Estos pueblos nos han permitido seguir la evolución de los salarios del maestro, así como la procedencia social de los mismos ${ }^{4}$.

Un tercer grupo lo forman los pueblos que cuentan con fundaciones destinadas a la enseñanza. El Catastro nos ofrece una imagen de estas fundaciones en un momento determinado, pero como casos ejemplares podríamos citar la fundación que en 1623 hace el Capitán Núñez Montenegro para que en la villa de Castropol haya un maestro que enseñe "a los pobres de la villa (...) de gracia»; en compensación recibirá ocho ducados cada año. Otra fundación muy similar es la que hace el Licenciado Toribio Garcia Cota en 1685, en Somió ${ }^{5}$.

Un cuarto grupo se detecta exclusivamente a través de los "contratos de enseñanza»; lo forman aquellas familias que quieren un maestro particular para sus hijos. Nosotros hemos encontrado bastantes ejemplos en Avilés a principio del siglo XVII ${ }^{6}$. Este grupo está formado, como era de esperar, por aquellos sectores socio-económicos que no sólo tenían posibilidades sino también tenían interés en acceder a la cultura escrita.

\section{NÚMERO Y DISTRIBUCIÓN DE LOS MAESTROS A MEDIADOS DEL SIGLO XVIII}

El siguiente cuadro pretende sintetizar la realidad, que presentamos de Occidente a Oriente y desde la costa hacia el interior.

\footnotetext{
3 A.G.S., Dir. G. Rentas, Catastro.

4 A. Dioc. Ov., Aller.

5 Biblioteca Asturiana, Gijón, Arch. Marcenado.

${ }^{6}$ Por ej., Esc. Luis Valdés Bango, A.H.P.O., C. 15.
} 


\begin{tabular}{|c|c|c|c|c|}
\hline \multirow{7}{*}{$\begin{array}{l}\text { OCCID. } \\
\text { COSTA }\end{array}$} & S. T. Abres ........... & 383 & 0 & 0 \\
\hline & Castropol .. & 3.275 & 2 & $1 \times 1.637$ \\
\hline & Figueras. & 148 & 0 & 0 \\
\hline & El Franco ............ & 884 & 0 & 0 \\
\hline & Coaña .............. & 634 & 2 & $1 \times 317$ \\
\hline & Navia $\ldots \ldots \ldots \ldots \ldots$ & 2.105 & 4 & $1 \times 526$ \\
\hline & Valdés $\ldots \ldots \ldots \ldots \ldots$ & 1.384 & 3 & $1 \times 461$ \\
\hline INIEHIU & Boal & 995 & 0 & 0 \\
\hline & Taramundi ........... & 405 & 0 & 0 \\
\hline & S. E. Oscos $\ldots \ldots \ldots$ & 217 & 0 & 0 \\
\hline & S. M. Oscos $\ldots \ldots \ldots$ & 224 & 0 & 0 \\
\hline & V. Oscos $\ldots \ldots \ldots \ldots$ & 152 & 0 & 0 \\
\hline & Illano ............... & 310 & 0 & 0 \\
\hline & Pesoz $\ldots . . . \ldots \ldots \ldots$ & 157 & 0 & 0 \\
\hline & Salime .............. & 51 & 0 & 0 \\
\hline & Grandas.....$\ldots \ldots$ & 313 & 0 & 0 \\
\hline & Ibias $\ldots \ldots \ldots \ldots \ldots$ & 526 & 0 & 0 \\
\hline & Allande.......... & 1.181 & 0 & 0 \\
\hline & Cangas y Corias .... & 825 & 1 & $1 \times 825$ \\
\hline & Tineo $\ldots . . . . . . . . . .$. & 2.309 & 3 & $1 \times 769$ \\
\hline & Cangas de Tineo .... & 2.818 & 2 & $1 \times 1.409$ \\
\hline & Cerredo y Degaña ... & 179 & 0 & 0 \\
\hline & Total Occidente ..... & 19.475 & 17 & $1 \times 1.145$ \\
\hline \multicolumn{5}{|l|}{ CENTRO- } \\
\hline \multirow[t]{7}{*}{ COSTA } & $\ldots \ldots \ldots \ldots \ldots$ & 2.440 & 3 & $1 \times 813$ \\
\hline & Castrillón ........... & 539 & 0 & 0 \\
\hline & Avilés $\ldots \ldots \ldots \ldots \ldots$. & 1.078 & 2 & $1 \times 539$ \\
\hline & Gozón . . & 1.118 & 2 & $1 \times 559$ \\
\hline & Carreño $\ldots \ldots \ldots \ldots$ & 964 & 1 & $1 \times 964$ \\
\hline & Gijón $\ldots \ldots \ldots \ldots \ldots$ & 2.425 & 2 & $1 \times 1.212$ \\
\hline & Villaviciosa $\ldots \ldots \ldots$ & 2.634 & 10 & $1 \times 263$ \\
\hline \multicolumn{5}{|c|}{ INTERIOR } \\
\hline & Belmonte......$\ldots$ & 215 & 0 & 0 \\
\hline & Somiedo ............. & 751 & 2 & $1 \times 375$ \\
\hline & Salas-Cornellana .... & 2.020 & 3 & $1 \times 673$ \\
\hline & Teverga ............. & 566 & 1 & $1 \times 566$ \\
\hline & Focella $\ldots \ldots \ldots \ldots$ & 110 & 0 & 0 \\
\hline & Yernes y Tameza & 122 & 0 & 0 \\
\hline & Candamo........ & 678 & 0 & 0 \\
\hline & Grado........... & 1.996 & 4 & $1 \times 499$ \\
\hline & Illas $\ldots \ldots \ldots \ldots \ldots$ & 258 & 0 & 0 \\
\hline & Las Regueras ....... & 523 & 0 & 0 \\
\hline & Proaza $\ldots \ldots \ldots \ldots$ & 376 & 1 & $1 \times 376$ \\
\hline & Quirós $\ldots \ldots \ldots \ldots \ldots$ & 762 & 0 & 0 \\
\hline & Riosa $\ldots \ldots \ldots \ldots \ldots$ & 371 & 1 & $1 \times 371$ \\
\hline & Morcín $\ldots \ldots \ldots \ldots$ & 402 & 0 & 0 \\
\hline
\end{tabular}




\begin{tabular}{|c|c|c|c|c|}
\hline & CONCEJO & VECINOS & MAESTROS & $\begin{array}{c}\text { RELACION } \\
\text { VECINO-MAESTRO }\end{array}$ \\
\hline INTERIOR & 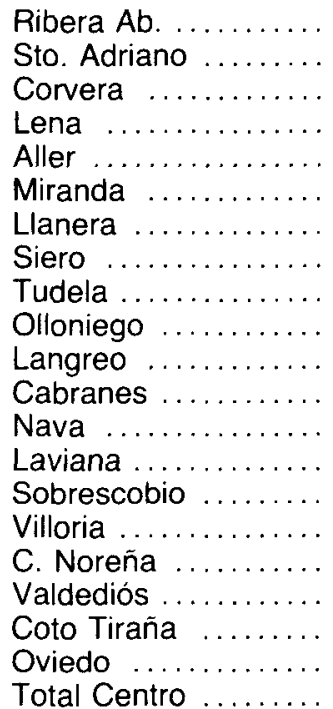 & $\begin{array}{r}82 \\
264 \\
379 \\
3.535 \\
1.776 \\
617 \\
767 \\
2.160 \\
252 \\
124 \\
1.550 \\
586 \\
724 \\
657 \\
324 \\
229 \\
395 \\
170 \\
196 \\
1.750 \\
36.885\end{array}$ & $\begin{array}{l}0 \\
0 \\
0 \\
6 \\
5 \\
0 \\
0 \\
2 \\
0 \\
1 \\
0 \\
1 \\
1 \\
0 \\
0 \\
0 \\
0 \\
0 \\
0 \\
2 \\
50\end{array}$ & $\begin{array}{c}0 \\
0 \\
0 \\
1 \times 589 \\
1 \times 355 \\
0 \\
0 \\
1 \times 1.080 \\
0 \\
1 \times 124 \\
0 \\
1 \times 586 \\
1 \times 724 \\
0 \\
0 \\
0 \\
0 \\
0 \\
0 \\
1 \times 875 \\
1 \times 737\end{array}$ \\
\hline ORIENTE & & & & \\
\hline $\operatorname{COSTA}$ & $\begin{array}{l}\text { Colunga } \ldots \ldots \ldots \ldots \\
\text { Caravia ............... } \\
\text { Ribadesella ......... } \\
\text { Llanes ............. }\end{array}$ & $\begin{array}{r}1.040 \\
135 \\
912 \\
2.775\end{array}$ & $\begin{array}{r}5 \\
0 \\
3 \\
13\end{array}$ & $\begin{array}{c}1 \times 208 \\
0 \\
1 \times 304 \\
1 \times 213\end{array}$ \\
\hline INTERIOR & 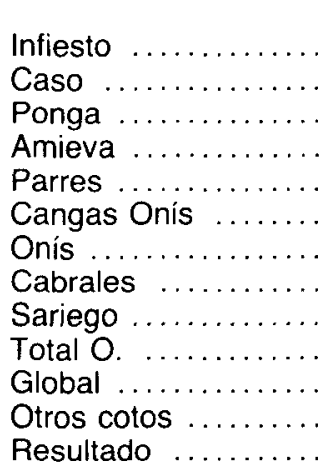 & $\begin{array}{r}2.276 \\
1.054 \\
488 \\
448 \\
917 \\
1.085 \\
404 \\
604 \\
221 \\
12.559 \\
68.719 \\
6.234 \\
74.962\end{array}$ & $\begin{array}{r}5 \\
1 \\
1 \\
1 \\
0 \\
4 \\
1 \\
6 \\
2 \\
42 \\
109 \\
3 \\
112\end{array}$ & $\begin{array}{l}1 \times 455 \\
1 \times 1.054 \\
1 \times 488 \\
1 \times 488 \\
0 \\
1 \times 271 \\
1 \times 404 \\
1 \times 100 \\
1 \times 110 \\
1 \times 294 \\
1 \times 630 \\
1 \times 669\end{array}$ \\
\hline
\end{tabular}

Fuente: A.G.S., dir. G. Rentas, catastro, Resp. Gene. 
De la tabla se desprenden algunas conclusiones de interés; en primer lugar, la media de un maestro por cada 669 vecinos engloba y enmascara una gran diversidad pues el porcentaje de maestros disminuye de oriente a occidente (desde 294 de la zona oriental por cada maestro a 737 en el centro y 1.145 en occidente) y de la costa hacia el interior. Esta tendencia es general, tanto para la zona occidental -aunque aquí estamos ya en una tierra de "maestro raro»- como para la central y oriental. Por otra parte, esta distribución está muy en relación con la estructura urbana o rural $y$, derivadamente, con áreas de economia de intercambios y de profesiones diversificadas. Los casos de Llanes y de Villaviciosa resultan altamente expresivos. Una tercera observación, probablemente innecesaria: ciertas ciudades y villas no dependian sólo de la oferta de estas escuelas por contar con monasterios que se dedicaban a la enseñanza.

Esta gran diversidad en la distribución de los maestros queda patente en la asignación de fondos concejiles para la enseñanza. La realidad es que la media de todos los concejos era de 1,3 por 100 de sus ingresos impositivos, pero las diferencias pueden sintetizarse con sólo comparar lo que gastan Avilés y Llanes, una vez segregado el monto de los encabezamientos. Pues bien, Avilés gasta el 14,4 por 100 y Llanes el 33,7 por $100^{7}$.

\section{LA VALORACIÓN SOCIAL DEL MAESTRO: EL SALARIO}

Conocemos las dotaciones de todos los maestros en el Catastro que arrojan una media de 345,5 reales por persona y año, si bien manifiestan

\footnotetext{
${ }^{7}$ No cabe duda que la relación maestro-vecinos parece que era mucho más favorable en Castilla que en Asturias y Galicia, debido a la estructura de su poblamiento. Por ej. C. LABRADOR HERRAIZ (“Los maestros de primeras letras en el Catastro del Marqués de la Ensenada", 11 Simposio P. Feijóo, Oviedo 1983, pp. 159-181) comprueba que los 10 pueblos por ella estudiados cuentan con su correspondiente maestro, tanto el mayor, de 345 vecinos, como el más pequeño, con tan sólo 30 . Sin embargo la comarca del Ulla, en Galicia, sólo tiene tres, tanto en la época del Catastro, como en la de Madoz, y el número de alumnos oscila entre 14 y 20 por cada maestro. No más de cuatro eran asimismo los que enseñaban en El Salnés del siglo XVIII, en donde había una población de cerca de 2.000 niños.

O. Rey Castelao: Aproximación a la historia rural en la comarca del Ulla (sS. XVII y XVIII), Univ. Santiago, 1981, pp. 165 y ss.

J. M. Perez Garcia: Un modelo de sociedad rural de Antiguo Régimen en la Galicia costera, Univ. Santiago, 1979. pp. 385 y ss.
} 
una gran dispersión que va desde un mínimo de 70 reales a un máximo de 800 . En todos los casos los preceptores de gramática se distancian notablemente, no bajando de 668 reales y llegando a alcanzar los 3.840 .

Podemos seguir también la evolución de estos salarios a lo largo de amplios períodos de tiempo en una comarca de interior y en la villa de Avilés, así como compararlos con los de otros oficios o profesiones liberales, lo que haremos tan sólo en años y fases significativas.

AVILES $^{8}$

\begin{tabular}{|c|c|c|c|c|c|}
\hline AÑOS & SALARIO MAESTRO & ID. MÉDICO & ORGANISTA & PREDICADOR & C. RELOJERO \\
\hline 1600 & $59 r$. & & & $200 \mathrm{r}$. & \\
\hline 1625 & $66 r$ & & & & \\
\hline 1645 & $132 \mathrm{r}$. & & & & \\
\hline 1654 & $154 \mathrm{r}$. & & & & \\
\hline 1664 & $154 \mathrm{r}$ & $3.300 \mathrm{r}$ & & & \\
\hline 1670 & 154 r. (1 maestro) & $3.300 \mathrm{r}$ & $400 \mathrm{r}$ & & $220 \mathrm{r}$. \\
\hline 1679 & $200 \mathrm{r}$ & & & & \\
\hline 1699 & $200 \mathrm{r}$ & $3.300 \mathrm{r}$ & & & $220 \mathrm{r}$. \\
\hline 1700 & $200 \mathrm{r}$. & & & $400 \mathrm{r}$. & \\
\hline 1706 & $200 \mathrm{r}$. & & & & $220 \mathrm{r}$. \\
\hline 1710 & $200 \mathrm{r}$. & & & & $220 \mathrm{r}$. \\
\hline 1743 & $300 \mathrm{r}$. & $3.000 \mathrm{r}$ & $440 \mathrm{r}$. & & \\
\hline 1750 & $300 \mathrm{r}$. & $3.000 \mathrm{r}$. & $440 \mathrm{r}$. & & $200 \mathrm{r}$. \\
\hline 1770 & $300 \mathrm{r}$. & $3.000 \mathrm{r}$ & $440 \mathrm{r}$. & $300 \mathrm{r}$. & $200 \mathrm{r}$. \\
\hline
\end{tabular}

Por su parte, el maestro-sacristán de Serrapio cobra 220 reales (132 como maestro y 88 reales como sacristán) en 1678 y la misma cantidad sigue cobrando en 1718, año en el que se le aumenta hasta $275 \mathrm{r}$. Mientras tanto el de Santibáñez de Riomiera cobra otros 220 reales en 1665 (110 por cada concepto), que tampoco se modifican hasta 1718, fecha en la que pasa a cobrar 300 reales.

${ }^{8}$ A.M.Av., Propios y Rentas. 
De estos datos resultan tres conclusiones importantes: la baja capacidad adquisitiva (como dato de referencia diremos que los $154 \mathrm{r}$. de 1654 equivalen a poco más que el costo de cinco fanegas de trigo); la inmovilidad que sufren durante largos períodos de tiempo al margen de las fluctuaciones de los precios; y el agravio comparativo frente a los salarios de otras profesiones. La situación, por otra parte, no es mejor para los maestros que se dedican a atender familias destacadas a tenor de los contratos que hemos manejado, pues sus honorarios oscilan a principios del XVII entre los 100 reales a pagar en tres plazos y los $143 \mathrm{r}$. a pagar una parte en metálico y otra en especie, ya bien sea en aceite o en libros ${ }^{9}$.

Este problema puede ser especialmente grave cuando depende de fundaciones antiguas apoyadas en censos o juros gravemente dañados, por ello es fácil comprender que se tratase de una enseñanza "subvencionada" sólo parcialmente, que obligaba a que las familias de los alumnos aportasen determinadas cuotas. Concretamente, la villa de Avilés permitía al maestro cobrar $1,5 \mathrm{r}$. a cada niño al que enseñase a leer y 3 $r$. si también le enseñaba a escribir ${ }^{10}$. En Santibáñez se le permite cobrar 12 r. anuales a cada niño "hijo de vecino", mientras que el maestro de Muñás (interior del Concejo de Valdés), que disfruta de un «situado» de 264 reales, no puede cobrar cosa alguna a los vecinos, pero sí a los forasteros que acudan a su escuela. Tal vez esta circunstancia explique que el número de alumnos todavía sea inferior al que cabía esperar y que podemos sintetizar en las palabras del visitador episcopal del Concejo de Aller a principios del siglo XVIII: "he sido informado que los veci-

9 Un ejemplo: Pedro Bertín se compromete a pagar "13 ducados pagados de esta manera, luego de presente una arroba de aceite en precio de $24 \mathrm{r}$. y $47,5 \mathrm{r}$. para día de carnestolendas que primero viene (...) en dos pagas de por mitad".

Por su parte, Doña Isabel de Valdés pagará los 13 ducados de la siguiente manera: $24,5 \mathrm{r}$. en tres libros ("el de Monterroso, una Filíica y un tratado de Moya, además de una pragmática»); los $118,5 \mathrm{r}$. restantes los entregará en tres plazos de $47,5 \mathrm{r}$. el primero y 35,5 r. cada uno de los dos siguientes.

En cambio, Alonso Alvarez de la Canal se compromete a pagar 100 r., entregando 33 por adelantado y el resto en dos plazos.

A.H.P.O., Esc. Valdés Bando, C. 15, f. 252 y ss.

No difieren estos salarios de los usuales en otras regiones, ni tampoco el hecho de que la mayor parte de los maestros rurales sean al mismo tiempo los sacristanes del pueblo. En los diez pueblos de la Alcarria, arriba citados, nueve de sus diez maestros simultaneaban ambos empleos y también aquí, como en Asturias, están muy mal pagados en relación con el resto de los oficios liberales. C. LABRADOR, op. cit.

10 A.M.Av., L. Acuerdos, 1605. 
nos no imbian sus hijos a la escuela, ni el maestro tiene que ocuparse ni exercitar su oficio" ${ }^{11}$.

\subsection{Función y control de los maestros. Contenido de la enseñanza}

Si comparamos la redacción de los Sínodos de Alvarez de Caldas (1607) y de González Pisador (1769) observaremos que nada ha cambiado. Veámoslo:

1607

“Pongan (los párrocos) cuydado con saber si los sacristanes o maestros de escuela que viviesen en sus parróquias enseñen la doctrina cristiana y virtud a los niños y aviendo algo digno de remedio cerca desto den aviso dello a nos, o a nuestro Provisor."
1769

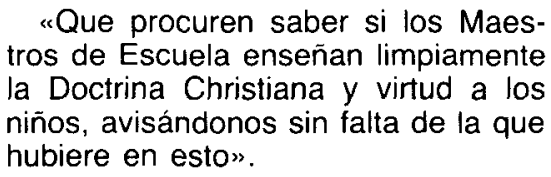

Pero si hay una diferencia de fondo en la actitud de la Corona, que impone sus condiciones a $\mathrm{G}$. Pisador para darle luz verde a la publicación del Sínodo, pues exige "que el Visitador y Ordinario Eclesiástico no debe mezclarse en el examen de habilidad de los Maestros de Niños, siendo solamente peculiar y privativo del mismo Ordinario en examinarle de Doctrina Christiana, enterarse de las costumbres de los Maestros, y el de estar a la vista, para que no enseñen por libros lascivos o deshonestos, pero se abstendrá de nombrarlos ni darles licencia" ${ }^{12}$ (El subrayado es nuestro).

Durante el siglo XVII el control de conocimientos corría a cargo frecuentemente de entidades eclesiásticas, sin embargo, en la segunda mitad del XVIII esta tarea la reclama el Estado que deja a la Iglesia únicamente el control doctrinal y moral. Al mismo tiempo, las entidades

$"$ A. Dioc. Ov., L. Fábrica de Santibáñez-Aller, f. 109.

12 Sinodo Ovetense de G. PISAdOR, Salamanca 1786, p. 1. 
oficiales toman la iniciativa en más alto grado no limitándose a contratar a quienes se acercaban a ofrecer sus servicios, como venía sucediendo durante el XVII, sino que anunciaban las vacantes y fijaban las fechas para la celebración de nuevas oposiciones ${ }^{13}$.

En el Sínodo de 1607 casi se identifican "sacristanes o maestros de escuela" porque asi sucedía en la realidad e incluso villas de importancia, como Avilés, solian acumular las funciones de sacristán o las de organista de la parroquia a las de maestro de niños, pagando más por el primer concepto que por el segundo ${ }^{14}$. Sin embargo, ya en el siglo XVII parecen descubrirse algunas generaciones de maestros, a tenor de los apellidos que figuran en la nómina de los avilesinos de dicho siglo ${ }^{15}$.

El origen de las fundaciones de enseñanza y la sociologia de los maestros permiten incidir mucho en el sentido de las primeras letras, cuyo nivel, en cualquier caso, es muy mediocre en sus planteamientos: enseñará "a leer y escribir y contar y la doctrina cristiana y ayudar a misa y los misterios de la fe" (fundación de Toribio García Coto); "enseñará a leer, escribir y contar» (fundación de Núñez Montenegro). La villa de Avilés, por su parte, marca dos niveles claramente diferenciados y valorados: básicamente, "enseñar a leer", por cuyo trabajo el maestro podrá cobrar un complemento de 1,5 reales a cada alumno; el segundo nivel, "enseñar a escribir», por lo que la cuota a cobrar de los alumnos podrá ser de 3 reales, si bien, en cualquiera de los casos se le impone la condición de uque cante en el coro los días de fiesta ayudando al sacristán» ${ }^{16}$.

Los contratos privados solían distinguir dos niveles, el uno dedicado a la enseñanza de «leer letra de romance procesada española usual (...) y a escribir letra bastardilla llana, de buena compostura y traza (...) y a

${ }_{13}$ Dos ejemplos de entre muchos: «pareció Alonso Yáñez de la Vega, vecino de Luarca, maestro de niños, y pidió se le de salario para usar el dho oficio (...). Acordose que se le de de salario en cada un año 6.000 mrs", A.M.Av., L. de Acuerdos, 1605.

En sesión de 18 de mayo de 1772 se informa ante los regidores avilesinos de la muerte del maestro titular y se solicita la fijación de fecha para "que se ha de celebrar las oposiciones para la dicha escuela", A.M.Av., L. Acuerdos, 1772.

14 Concretamente, en 1600 se pagan $2.000 \mathrm{mrs}$. al maestro y en 1625 se le pagan $2.244 \mathrm{mrs}$. Sin embargo, en 1605 al maestro-sacristán se le asigna un salario de 6.000 mrs. A.M.Av., L. Acuerdos y L. de “Cuentas y Procuración General». L.1.

15 A.H.P.O., Esc. Valdéz Bango, C, 15, f.253.

A.M.Av., L. Acuerdos de la década de 1660 y L. de "Propios y Rentas".

${ }^{16}$ A.M.Av., L. Acuerdos, 1605. 
contar por entero sin quebrados tres reglas de quenta de guarismo, que son sumar y restar y multiplicar»; por encima de este nivel, todo aquello que se enseñare deberá ser tasado por peritos, quienes fijarán la retribución pertinente ${ }^{17}$.

Parece desprenderse de todo ello que un primer nivel se sitúa en la lectura y el segundo -claramente diferenciado- en la escritura, lo que resulta bastante explicable y que coincide con la realidad escocesa, en donde el objetivo básico era saber leer para poder acceder a la lectura de la Biblia que, en nuestro caso, podríamos traducir por el aprendizaje de la Doctrina Cristiana, de cuyo conocimiento deben rendir cuenta anualmente todos los fieles. Ejemplos han llegado hasta nosotros de gentes que si "sabian leer la cartilla» ${ }^{18}$, pero no escribir.

\section{NIVEL DE ALFABETIZACIÓN}

Partimos de la diferencia, arriba apuntada, entre capacidad de lectura y capacidad de escritura, que pueden no coincidir. Por otra parte, sigue siendo un problema la valoración de determinadas fuentes que habitualmente vienen utilizándose para conocer los niveles de alfabetización. Nos estamos refiriendo a las firmas en los contratos notariales. Sin embargo, hoy por hoy es la única fuente capaz de proporcionar datos a gran escala, sobre todo para Asturias, en donde no contamos con el censo de $1635^{19}$.

Hubiera sido deseable proceder a la obtención de una muestra de todas las áreas en las que hemos diferenciado el espacio asturiano a nivel de reparto de los maestros, pero ni el tiempo ni las fuentes nos lo permitieron, sin embargo las muestras practicadas pueden resultar interesantes e indicativas. Veamoslas.

17 Vid. nota 8.

18 Vid. Rob. Houston: “The literacy myth? Illiteracy in Scotland, 1630-1760", Past and Present, 96, 1982, pp. 82 y ss.

T. C. SMOUT: "Born again at Cambuslang: New evidence on popular religion and literacy in eighteenth century Scotland", Past and Present, 97, 1982, pp. 121 y ss.

${ }_{19}$ En torno a sus problemas puede verse a $L$. STONE: "Literacy and Education in England, 1640-1900", Past and Present, 42, 1969, pp. 69 y ss. 


\begin{tabular}{|cccc|}
\hline & & FIRMAN & NO FIRMAN \\
\hline \multirow{2}{*}{ OVIEDO } & f. XVII & $220(53,5 \%)$ & $191(46,4 \%)$ \\
& f. XVIII & $192(50,5 \%)$ & $188(49,4 \%)$ \\
AVILES & f. XVII & $278(38,7 \%)$ & $453(61,9 \%)$ \\
& f. XVIII & $160(50,6 \%)$ & $156(49,3 \%)$ \\
\hline
\end{tabular}

El resultado puede parecer algo contradictorio y sin embargo creemos que es muy razonable. La mejoría de Avilés se corresponde con la progresiva mejoría que consigue el sector artesanal y del comercio del cobre, fenómeno que se pone de manifiesto ya a lo largo del siglo XVII, como puede verse en la tabla siguiente:

\begin{tabular}{|ccc|}
\hline AVILÉS, SIGLO $X V I I$ & P. SIGLO & F. SIGLO \\
\hline & & \\
Firman $\ldots \ldots \ldots \ldots \ldots \ldots \ldots \ldots$ & $23 \%$ & $40 \%$ \\
No firman $\ldots \ldots \ldots \ldots \ldots \ldots$ & $76 \%$ & $60 \%$ \\
\hline
\end{tabular}

Pero esta mejoria se apoya precisamente en los sectores medios, frente al ligero retroceso de los más acomodados, como se pone de manifiesto en la siguiente tabla:

\begin{tabular}{|c|c|c|c|}
\hline & & $\begin{array}{c}\text { VENTAS/OBLIG. DE MÁS } \\
\text { DE } 20 \text { DUC. }\end{array}$ & $\begin{array}{c}\text { ID. DE MENOS DE } 20 \\
\text { DUC. }\end{array}$ \\
\hline Firman & $\begin{array}{l}\text { p. siglo } \\
\text { f. siglo }\end{array}$ & $\begin{array}{l}43,8 \% \\
34,5 \%\end{array}$ & $\begin{array}{l}25,3 \% \\
26,8 \%\end{array}$ \\
\hline
\end{tabular}


Este avance de los sectores medios no parece haberse dado de la misma forma en la ciudad de Oviedo, en donde, en cambio, si tienen fácil acceso al notario.

Los resultados aqui presentados hubieran resultado más negativos si abordásemos otras comarcas; sin embargo, tanto el avance de los sectores medios ${ }^{20}$, como los resultados globales resultan bastante parecidos a los de otras regiones, que han llegado a nuestro conocimiento ${ }^{21}$.

\section{LA PRESENCIA DEL LIBRO}

Este problema se puede plantear desde una doble perspectiva: la presencia del libro en el conjunto de la población, con lo cual se trataría de conocer cuántos y quiénes leían en un determinado momento; segundo, cual era el contenido de las bibliotecas importantes, para descubrir qué leían los grupos destacados de la sociedad que realmente tenían peso intelectual. Nosotros vamos a tratar de aproximarnos un poco a ambos aspectos.

Sobre un total en torno al millar de inventarios de campesinos hemos comprobado que el libro era totalmente desconocido pues no hemos encontrado ninguna biblioteca.

${ }^{20}$ En la comarca gallega del Ulla firma el 13,3 por 100 en el siglo XVII; el 21,6 por 100 entre $1700-1749$ y el 50 por 100 entre $1750-1799$.

En La Lanzada lo hacen a mitad del XVIII el 66 por 100 de los compradores y el 41,1 por 100 de los vendedores.

En la comarca leonesa de La Bañeza saben firmar alrededor del 20 por 100 en el siglo XVII y entre el 40 y el 50 por 100 en el XVIII.

Vid. O. Rey Castelao, cit., p. 166; J. M. Perez Garcia, op. cit., p. 385; L. Rubio Pérez: La Bañeza y su tierra, 1650-1850, Universidad de León, 1987, pp. 481-483. Otra visión documental del problema apud. B. Bennassar y otros: Origenes del atraso económico español, Ariel, 1985, pp. 147 y ss.

Un contraste significativo lo ofrece $V$. MUNNE ( $E$ El nivel d'alfabetizació de la població de Mataró a mitya del sgle XVIil'. L. C. H. ${ }^{a}$ de Cataluña, 2, pp. 666 y ss.) con un resultado del 34,3 por 100 de firmantes, que es una media resultante del 100 por 100 de los sectores privilegiados, el 95 por 100 de los comerciantes, el 57 por 100 de los artesanos y el 29 por 100 de los labradores y marineros. Los datos proceden únicamente de las fuentes testamentarias.

${ }^{21}$ Los datos asturianos proceden fundamentalmente de los siguientes fondos documentales del A.H.P.O., Protoc., C. 118, 124, 125, 128, 285, 297, 316, 332, 402, 503, 508, 509, $511,532,534,567,595,596,746,747,757,758,795$. 
Una segunda muestra, ahora de un centenar de inventarios, sobre el mundo urbano y clérigos de toda procedencia, el resultado ha sido de siete bibliotecas, cuatro de las cuales corresponden a clérigos (con 69,34 y 4 volúmenes, respectivamente, mientras que el último sólo disponía del brebiario) y tres a laicos (con 41 volúmenes el uno, seis y "otros libros" el segundo y dos de "estudio de gramática» el tercero). La temática es la habitual: tratados jurídicos, teológicos y hagiográficos. Pero, al mismo tiempo, había clérigos sin libro alguno "porque decían eran pobres"; y los mercaderes avilesinos, a su vez, no contaban con libros entre sus bienes. No cabe duda que en un medio así los sermones y las homilías eran los únicos vehículos que hacian llegar las ideas al público.

De entre los sectores privilegiados he seleccionado el inventario de un párroco, miembro de una destacada familia, correspondiente a 1778; el del Conde de Toreno de 1804, el del Marqués de Santa Cruz, de 1788 $y$, finalmente, el registro de libros que van adquiriendo los monjes del Colegio de San Vicente (residencia del P. Feijóo) entre 1753 y $1805^{22}$.

La biblioteca del párroco sumaba 40 títulos y 121 volúmenes, que fueron valorados en 1.850 reales. Era muy poco diversificada temáticamente pues no habia en ella títulos de ciencias, matemáticas, derecho, ni siquiera sermonarios o novenas; pero si era rica en tratados doctrinales, obras de historia o de información diversa, llegando en esto a niveles muy aceptables. No faltaban colecciones de Concilios, ediciones de la Biblia, obras del P. Flórez o el ineludible Evangelio en triunfo. Pero también contaba con nueve tomos de El espiritu de los mejores diarios; dos tomos de la Estafeta de Londres; una colección de Mercurios, y 11 tomos de la Enciclopedia, sin otra precisión al respecto sobre la misma ${ }^{23}$.

La Biblioteca del Conde de Toreno, de 1804, me parece de lo más interesante para llegar a conocer las fuentes de las que bebía una de las figuras ilustradas que más ha trabajado por Asturias desde Asturias. Como es bien sabido, el Conde recorrió ampliamente el occidente de la región para buscar y analizar los yacimientos minerológicos, reuniendo muestras que remitió a Madrid para su correspondiente análisis. Patro-

${ }^{22}$ Los fondos corresponden a la Biblioteca Asturiana de Gijón, Ms. 312; Biblioteca Universidad Oviedo, Fondo C. de Toreno, L. 34; A. Marcenado, Casa de Navia, L. 2 n. ${ }^{\circ}$ 34; y A. San Pelayo, Fondos de San Vicente.

${ }^{23}$ Vid. para Santiago O. REY CASTELAO: «El clero compostelano a fines del siglo XVIII:

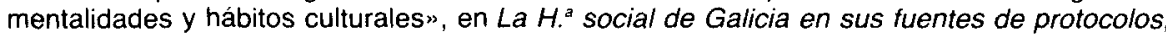
Santiago, 1981, p. 495 y ss. 
cinó asimismo e impulsó la Sociedad de Amigos del País a la que envía estudios y trabajos sobre agricultura, industria y comunicaciones, al mismo tiempo que se esforzó por ponerla en contacto con otras Sociedades pioneras. De todos modos, la lectura de alguno de sus trabajos evidencian un alto grado de idealismo sin base en la realidad, puesto que, de hacerle caso, Asturias reuniria las mejores condiciones para el cultivo del almendro, del olivo, del cacao, además de limoneros y naranjos. En sintesis, él cree que puede producir todo aquello que tiene alto valor en el mercado y que precisamente no se produce aquí.

Pero, al margen de este justificable voluntarismo, sus planteamientos teóricos ponen en evidencia una gran preparación e información por su parte.

Pues bien, su biblioteca constaba únicamente de 114 títulos y de 339 volúmenes, pero de gran calidad y diversidad. En el campo de las Ciencias Naturales, de la agricultura e industria, figuraban obras de Buffon, Bowlwas, Ortega, Carballo, Campomanes. La Historia era la mejor representada: Mariana, Risco, Duchesne, Garibay. Otras, a caballo entre la geografía, la historia y las ciencias: Pons, Campillo (Atlas), Jorge Juan (Observaciones y Viaje a América), B. Valdés (Derrotero de las costas de España). No podía faltar el omnipresente Pluche (Espectáculo de la Naturaleza). Figuraban también Sempere y Guarinos y la Estafeta de Londres (dos tomos). No era muy importante, en cambio, la nómina de autores clásicos pre-romanos (Cicerón y $\mathrm{M}$. Aurelio) y españoles (Quevedo y Cervantes - Obras de, y Don Quijote). También contaba con Fleury, Conde de Toreno, las Memorias Históricas del Principado de Asturias. El año cristiano (18 tomos), la Biblia y el Barbadiño (Verdadero método de estudiar), etc. Pero sorprende la ausencia total de obras de pensamiento, sobre todo extranjero, así como el silencio sobre el P. Feijóo.

Nos detendremos algo más en la biblioteca del quinto Marqués de Santa Cruz, cuyo inventario está fechado en 1788. No nos puede pasar desapercibido que se trata de otra de las familias que dieron lustre a Asturias en el siglo XVIII con el "gran Santa Cruz" de las Reflexiones militares y de la Rapsodia, al que suceden otros, como este al que corresponde el inventario, que desarrollaron una gran actividad e inquietud científica.

La biblioteca se compone de 905 títulos y 1.605 volúmenes, tasados en 1.005 libras, nueve sueldos y cuatro dineros. De ella conocemos prác- 
ticamente todos los detalles sobre la mayor parte de los libros: título, autor, formato, lengua y lugar de edición.

Empecemos por la fecha, lengua y lugar de edición, porque se trata de tres variables que nos conectan con las redes de suministro y con el mayor o menor grado de actualización del dueño.

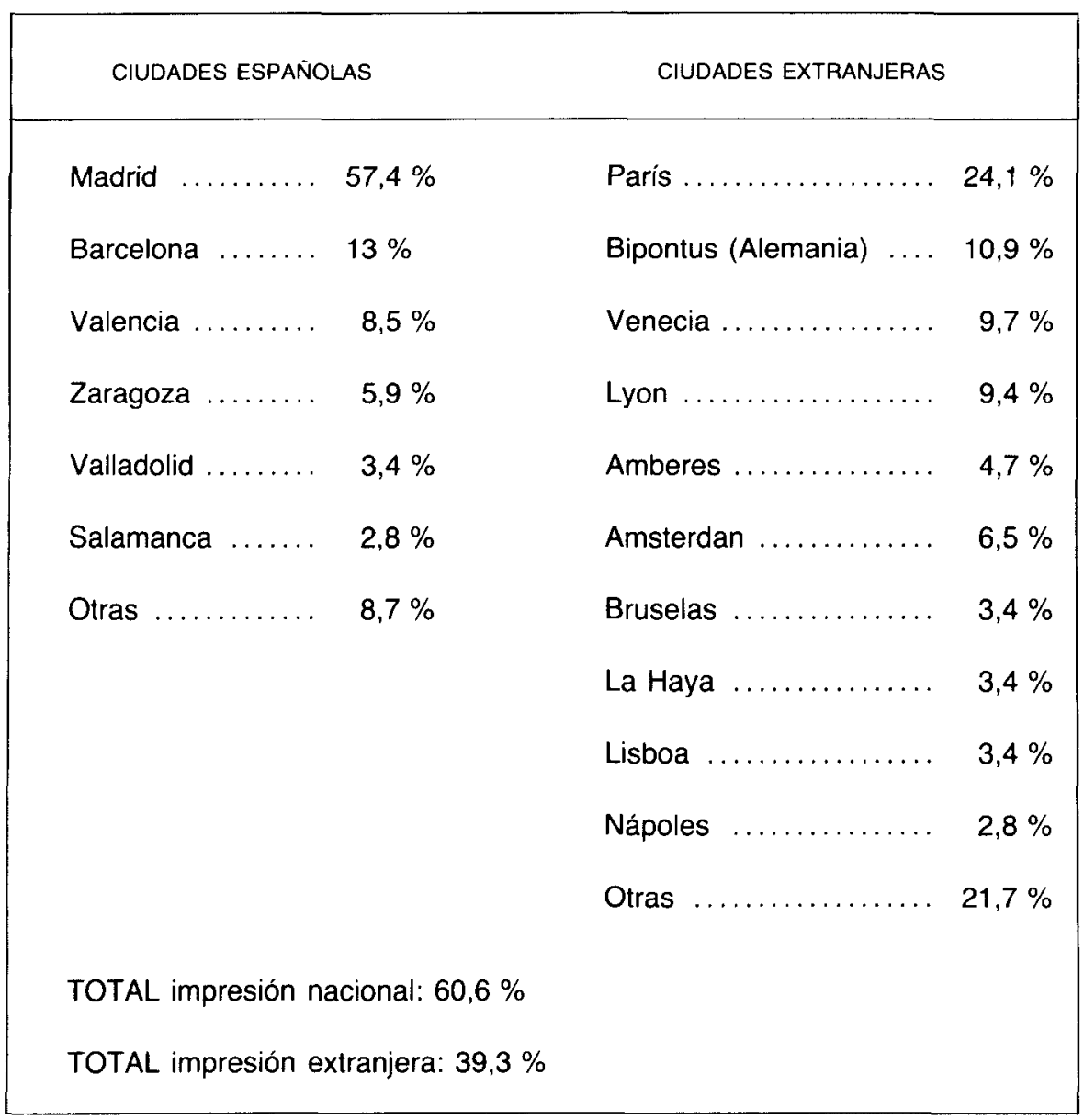




\begin{tabular}{|rrrr|}
\hline FECHA DE EDICION & & LENGUA DE EDICION \\
\hline 1499 & $0,3 \%$ & español & $62,8 \%$ \\
$1500-1549$ & $1,6 \%$ & francés & $13,6 \%$ \\
$1550-1599$ & $8,2 \%$ & latín/griego & $13,9 \%$ \\
$1600-1649$ & $19,1 \%$ & italiano & $4,3 \%$ \\
$1650-1699$ & $13,3 \%$ & portugués & $1,1 \%$ \\
$1700-1749$ & $19,9 \%$ & catalán & $0,2 \%$ \\
$1750-1779$ & $24,8 \%$ & no dicen & $3,8 \%$ \\
$1780-$ & $12,5 \%$ & & \\
\hline
\end{tabular}

A partir de estos tres datos se pueden sacar algunas conclusiones de cierto interés. Primera, el alto grado de actualización que mantiene el Marqués, pues el 12,5 por 100 de sus libros se publicaron en los últimos años de su vida, y se trata además de obras procedentes de la ciudad alemana de Bipontus (¿latinización de Zbwei-Bröcken?). Segunda, la importancia de cada centro de edición, tanto nacional como extranjero, coincide con el escalonamiento que ya conociamos, salvo esa ciudad alemana, que, al parecer propulsó las ediciones de obras clásicas durante el siglo XVIII. Tercero, la importancia de cada lengua de impresión concede una gran importancia al español, pero mantiene una discreta presencia el francés y más reducida el italiano, mientras que el latín griego es importante, pero muy inferior al de la Biblioteca de Jovellanos e incluso al 19,6 por 100 de la de Meléndez Valdés ${ }^{24}$. La sorpresa parece estar en la ausencia de títulos en inglés, pero creo que se trata de fallos-silencios del inventario, puesto que alguna de ellas deberian estar en esta lengua, como la obra de Franklin, De Constitutines, publicada en Filadelfia, en el año 1778. Destaca, finalmente, la dimensión de la biblioteca con sus 905 títulos y 1.605 volúmenes, muy distanciada de las de

${ }^{24}$ G. Demerson: Meléndez Valdés, Taurus, 1971, p. 140. 
Jovellanos y Meléndez Valdés con 857 y 352 respectivamente y por encima también de la media de las 31 bibliotecas de miembros del Consejo de Castilla ${ }^{25}$.

Queda por abordar, bien que sumariamente, la temática de esta biblioteca, eludiendo todo tipo de discusión sobre las ventajas e inconvenientes de ciertas clasificaciones. Aceptamos una que nos sirva de mecanismo de aproximación.

\begin{tabular}{|c|c|c|c|}
\hline \multicolumn{2}{|l|}{ MATERIAS } & \multicolumn{2}{|l|}{ MATERIAS } \\
\hline Literatura clásica ........ & $12 \%$ & $\begin{array}{l}\text { Matemáticas/Ciencias } \\
\text { nat./Física - Quím. ........ }\end{array}$ & $4,3 \%$ \\
\hline Literatura española & $9,6 \%$ & Derecho & $3 \%$ \\
\hline $\mathrm{H}^{\text {a }}$ civil $\ldots \ldots \ldots$ & $27 \%$ & Pensamiento & $6,3 \%$ \\
\hline H. Eclesiástica ......... & $1,3 \%$ & Economía & $7,4 \%$ \\
\hline Teología & $3,5 \%$ & Técnica militar ... & $17 \%$ \\
\hline Devoción $\ldots \ldots \ldots \ldots \ldots$ & $2,3 \%$ & Geografía/viajes ...... & $2,7 \%$ \\
\hline & & Otros $\ldots \ldots$ & $3,5 \%$ \\
\hline
\end{tabular}

Destaca la riqueza de sus fondos de literatura clásica. Diriamos que no falta ninguno de importancia (César, Ovidio, Séneca, Cicerón, Virgilio, Horacio, Tito Livio, Terencio, Marco Aurelio, Tácito, Plutarco, Homero, Tucidides, Jenofonte, Tolomeo, Lucano, Quinto Curcio, Josefo, etc.). Algo inferior era la presencia de literatura española, aunque importante su selección (no falta el Lazarillo; está casi todo lo de Fray Luis de Granada, 464-467. 
Fray Luis de León, lo mismo que Lope de Vega, Cervantes, Quevedo, etcétera.) ${ }^{26}$.

La representación de las obras de matemáticas y ciencias naturales era más que aceptable con el $\mathrm{P}$. Zaragoza (Aritmética, Trigonometría, Instrucción matemática), Tosca, Cerdá (Aritmética, Geometria), Capmany, Ozanam, Eizaguirre, Buffón, Bowles, Pellicer, etc.

Magnífico el apartado de Historia, incluido su conexión con Mondéjar y Nicolás Antonio, hasta llegar a Mayáns (Cartas, Madrid, 1734, Historias Fabulosas, Valencia 1752 o ¿1762? ¿Censura de H. ${ }^{a}$ S Fabulosas, de N. Antonio?). En el camino aparecen Mariana, Flórez, Isla, Masdeu, Zurita, Morales, Sandoval, Risco, Duchesne y muchos otros.

Del resto de sus libros me limitaré a advertir que contaba con 36 volúmenes de L'Enciclopedie Methodique, pero también con la Defensa de Forner, al igual que para 1635 disponía de Francia engañada, Francia respondida. Pero no había nada de Feijóo, aunque sí de Santa Cruz (Rapsodia) y de Sarmiento (Obras Póstumas).

Esta es una breve presentación de una biblioteca que, en su formato, se presentaba así: 29,3 por 100 en folio; 36,6 por 100 en $4 .{ }^{\circ} ; 32,9$ por 100 en $8 .^{\circ} ; 8,2$ por 100 en formatos menores y 1,2 por 100 en manuscritos.

Para terminar, una aproximación a la biblioteca que van formando los benedictinos ovetenses desde 1741 hasta 1805, cuya información está tomada de la contabilidad que cada cuatro años rinde el Monasterio ante el Capitulo General. El total de dinero invertido en libros fue de 54.292 r. con un máximo entre 1765-1769 (13.262 r.) y un minimo de 0 r. en 1749-53, 1777-81 y 1801-1805. La media de gasto en libros fue de 848 r. por año, con un total del 0,55 por 100 de los gastos globales. En resumen, 195 títulos y 697 volúmenes fueron los adquiridos ${ }^{27}$.

El análisis de los fondos no aporta ninguna luz especial sobre este foco de cultura que daba cobijo al P. Feijóo. Aparecen dos áreas que

${ }^{26}$ Véase el contraste con la estructura de las 16 bibliotecas especialmente analizadas por L. C. Álvarez Santalo: "Librerías y Bibliotecas en la Sevilla del siglo XVII", $A$. del II $C$. de M.A 2, Santiago, 1984, pp. 165 ss. También P. MolAS RIBALTA: “Religiosidad y cultura en Mataró. Nobles y comerciantes en el sigio xvlllm, Ibidem, pp. 95 y ss.

${ }_{27}$ A. Monasterio de San Pelayo, Fondos de San Vicente, L. de Depósito. 
centraban su atención: la patrística y la historia. Año tras año van llegando las obras de San Bernardo, Anselmo, Buenaventura, Cipriano, Tertuliano, Isidoro, Orígenes, Atanasio, Basilio, Gregorio Magno, Jerónimo, Ambrosio, Agustín. También adquieren todo lo de los Bollandistas, Maurinos, Mabillon, Nicolás Antonio; la Colección de Concilios, Mariana, Flórez, Risco, Morales, Sandoval y Eusebio de Cesárea. Como complemento llegan Santa Teresa, Juan de Avila, Suárez y Scoto, así como Ulloa (Viaje a América), Ponz, Nipho, El Diccionario de Treboux, el Tratado de Regalía de la Amortización, de Campomanes y los inevitables Espectáculo de la Naturaleza y el Evangelio en triunfo. De la literatura española, Quevedo, y del conflicto entre la Corona y los jesuitas, el Expediente del llustrísimo Carvajal, Obispo de Cuenca y 15 tomos de Palafox.

En síntesis, una biblioteca que responde bien a las necesidades de un centro de estudios monásticos, que entonces es colegio de su Orden, sin hacer incursiones en otros temas que podrian ser de actualidad en aquellos momentos. Pienso que debían contar con otros medios de lectura. Tampoco aquí se encuentra cita alguna del P. Feijóo.

\section{CONCLUSIÓN}

Una región con un reparto muy desigual de los maestros de primeras letras, los valora socialmente muy por debajo de la casi totalidad de otros oficios o profesiones liberales. Consiguientemente el porcentaje de analfabetos es muy elevado, al igual que sucede en el resto del mundo campesino español, pero que mejora globalmente a lo largo de los siglos XVII y XVIII. Por otra parte, el libro era un bien demasiado escaso salvo entre algunas minorías muy cualificadas con las que contó Asturias en el XVIII y que exportó generosamente. En esos grupos existian bibliotecas importantes tanto por sus dimensiones, como por la calidad de sus fondos, que explican la formación que demostraban tener sus titulares. 